\title{
Maximizing Productivity and Reducing Environmental Impacts of Full-Scale Algal Production through Optimization of Open Pond Depth and Hydraulic Retention Time - Supporting information
}

Quentin Béchet $^{\mathrm{a}, \mathrm{b}, *}$, Andy Shilton ${ }^{\mathrm{a}}$, and Benoit Guieysse ${ }^{\mathrm{a}}$

${ }^{a}$ School of Engineering and Advanced Technology, Massey University, Private Bag 11 222, Palmerston North 4442, New Zealand

${ }^{\mathrm{b}}$ INRIA BIOCORE, BP 9306902 Sophia Antipolis Cedex, France

* Corresponding author

Telephone: +33492387174

Fax: + 33492387858

E-mail: quentin.bechet@inria.fr

14 Pages

6 Figures

2 Tables 


\section{S1: Description of the productivity model}

\subsection{Introduction}

This supporting information describes how the productivity was predicted in open ponds by the Béchet model from the knowledge of the hourly weather data at the locations considered. Section 1.2 summarizes the different assumptions of the model and details the main model equations. Section 1.3 lists the values of the biological parameters of the model. Section 1.4 explains how the light distribution was determined in the culture broth of raceway ponds. Finally, Section 1.5 briefly describes how the temperature variations were computed from the model of Béchet et al. ${ }^{1}$.

\subsection{General expression of the productivity model}

The raceway ponds considered in this study were operated in a semi-continuous regime, i.e. a fraction of the broth was extracted everyday from the culture. The yearly productivity in a pond (in $\mathrm{kg} \mathrm{yr}^{-1}$ ) was therefore expressed as follows:

$P_{\text {year }}=\left(X_{\text {end }} \bigvee_{\text {end }} \quad X_{\text {ini }} \aleph_{\text {ini }}\right)+{ }_{i=1}^{365} X_{s, i} \aleph_{s, i}$

where $X_{\text {end }}$ and $X_{\text {ini }}$ are the final and initial algal concentrations $\left(\mathrm{kg} \mathrm{m}^{-3}\right)$, respectively, $V_{\text {end }}$ and $V_{i n i}$ are the final and initial system volumes $\left(\mathrm{m}^{3}\right)$, respectively, $X_{s, i}$ is the algal concentration at day $i$ at the time of sampling $\left(\mathrm{kg} \mathrm{m}^{-3}\right)$ and $V_{s, i}$ is the volume of water sampled at day $i\left(\mathrm{~m}^{3}\right)$. In order to determine the values of the cell concentration over time, the following differential equation was solved:

$\frac{d X}{d t}=\frac{P}{V}$

where $X$ is the algal concentration $\left(\mathrm{kg} \mathrm{m}^{-3}\right)$ over the time $t(\mathrm{~s}), P$ is the instantaneous productivity $\left(\mathrm{kg} \mathrm{s}^{-1}\right)$ and $V$ is the culture volume $\left(\mathrm{m}^{3}\right)$.

The productivity model expressing $P$ at any time $t$ was based on the assumption that the rate of photosynthesis of single algae cells is a function of the light intensity seen by each cell and the temperature of the culture medium (assumed homogenous). This type of model 
(categorized as a 'Type-II model' by the review of Béchet et al. $^{2}$ ) expresses the productivity as follows:

$$
P=P_{V} \frac{{ }_{X} I_{l o c}}{K+{ }_{X} I_{l o c}} X \times d V \quad X V \quad(\mathrm{~S} 1-\mathrm{S} 3)
$$

where $P_{m}$ is the maximal specific productivity $\left(\mathrm{kg} \mathrm{kg}^{-1} \mathrm{~s}^{-1}\right), \sigma_{X}$ is the extinction coefficient $\left(\mathrm{m}^{2}\right.$ $\left.\mathrm{kg}^{-1}\right), I_{l o c}$ is the local light intensity at the location considered $\left(\mathrm{W} \mathrm{m}^{-2}\right.$, as photosynthetically active radiation or PAR), $K$ is the half-saturation constant $\left(\mathrm{W} \mathrm{kg}^{-1}\right), X$ is the cell concentration $\left(\mathrm{kg} \mathrm{m}^{-3}\right), V$ is the culture volume $\left(\mathrm{m}^{3}\right)$, and $\lambda$ is the respiration coefficient $\left(\mathrm{kg} \mathrm{kg}^{-1} \mathrm{~s}^{-1}\right)$.

In order to determine the instantaneous productivity at any time of the year, it was necessary to account for the variations of the biological parameters over time due to temperature change and the variation of the light distribution in the culture due to the change of the algal concentration. As a result, the calculation of the yearly productivities was a four-step approach:

1. The temperature of the pond was calculated at every time step of the simulation by using the model of Béchet et al. ${ }^{1}$;

2. The biological parameters $P_{m}, K$, and $\lambda$ at each time step were determined from the temperature profile determined during Step 1;

3. The light distribution was determined at each time step as a function of the instantaneous algal concentration and the solar irradiance at each time step of the simulation.

4. The instantaneous productivity was calculated by using Equation S1-S3 and the algal concentration at the end of the time step was determined by using Equation S1-S2.

Determining the instantaneous productivity at every time of a year was performed numerically by using a first-order forward Euler scheme. The three following sections detail how steps 1 to 3 were performed.

\subsection{Biological model}

The values of $P_{m}, K$ and $\lambda$ were experimentally determined by Béchet et al. ${ }^{3}$ by measuring the rate of oxygen production in the light and consumption in the dark. The values of $P_{m}$ and $\lambda$ shown in Table S1-S1 are therefore expressed as $\mathrm{kg} \mathrm{O}_{2} \mathrm{~kg}^{-1} \mathrm{~s}^{-1}$. In order to convert oxygen 
productivities into biomass productivities, Béchet et al. ${ }^{3}$ suggested using the following conversion coefficients:

- $\quad P_{m}{ }^{\prime}[\mathrm{kg} / \mathrm{kg}-\mathrm{s}]=0.76( \pm 0.09) P_{m}[\mathrm{~kg} \mathrm{O} / \mathrm{kg}-\mathrm{s}]$

- $\lambda^{\prime}[\mathrm{kg} / \mathrm{kg}-\mathrm{s}]=0.76( \pm 0.09) \lambda[\mathrm{kg} \mathrm{O} / \mathrm{kg}$-s $]$ in light conditions

- $\quad \lambda^{\prime}[\mathrm{kg} / \mathrm{kg}-\mathrm{s}]=0.94 \lambda[\mathrm{kg} \mathrm{O} / \mathrm{kg}-\mathrm{s}]$ in dark conditions

The values of $P_{m}, K$ and $\lambda$ at any temperature were linearly interpolated between the values shown in Table S1-S1.

Table S1-S1: Values of the model parameters $P_{m}, K$ and $\lambda$ at different temperatures ${ }^{3}$ (values in parenthesis indicate the confidence interval at 95\% computed through Monte-Carlo simulations).

\begin{tabular}{lcccccc}
\hline Temperature $\left({ }^{\circ} \mathbf{C}\right)$ & $\mathbf{5 . 5}$ & $\mathbf{1 4 . 2}$ & $\mathbf{2 1 . 7}$ & $\mathbf{2 9 . 3}$ & $\mathbf{3 8 . 0}$ & $\mathbf{4 2 . 1}$ \\
\hline$P_{m}\left(10^{-5} \mathrm{~kg} \mathrm{O}_{2} / \mathrm{kg}-\right.$ & $1.25(0.10)$ & $2.99(0.27)$ & $4.90(0.44)$ & $6.87(0.68)$ & $8.64(0.94)$ & 0 \\
$\mathrm{~s})$ & & & & & & \\
\hline$K(\mathrm{~W} / \mathrm{kg})$ & $540(117)$ & $1580(290)$ & $3180(530)$ & $5590(1050)$ & $8510(1670)$ & $\mathrm{NA}$ \\
\hline$\lambda\left(10^{-6} \mathrm{~kg} \mathrm{O} / \mathrm{kg}-\mathrm{s}\right)$ & 0 & $1.36(0.12)$ & $1.95(0.18)$ & $2.11(0.18)$ & $2.33(0.20)$ & 0 \\
\hline
\end{tabular}

As the productivity model was validated in photobioreactors only, it is difficult to estimate the accuracy of the model predictions in open ponds. However, the productivity was validated against two data sets. First, the model showed an accuracy of $+/-15 \%$ over 163 days of cultivation in bench-scale photobioreactors surrounded by light bulbs and operated under constant light intensity (range: $30.6-74.3 \mathrm{~W} \mathrm{~m}^{-2}$, as photosynthetically active radiation or PAR) and temperature (range: $10-30^{\circ} \mathrm{C}$; see Béchet et al. ${ }^{3}$ ). The productivity model was then validated in outdoor photobioreactors with an accuracy of $+/-8.4 \%$ over 148 days of cultivation in New Zealand covering a large range of temperatures $\left(0-37.2^{\circ} \mathrm{C}\right)$ and light intensities $\left(0-374 \mathrm{~W} \mathrm{~m}^{-2}\right.$, as PAR; see Béchet et al. $\left.{ }^{4}\right)$. These results indicate that the model can predict productivity for different geometries, under variable weather conditions, and over the full ranges of light and temperature conditions experienced in open ponds. For these reasons, the model should theoretically predict productivity in open ponds with an accuracy on the order of $+/-10 \%$. Model predictions are in agreement with values reported in the literature as detailed in the main manuscript. 


\subsection{Light distribution in the open pond}

The light distribution in small cultivation vessels used for model calibration was assumed to follow the Beer-Lambert law that can be expressed as follows ${ }^{3}$ :

$$
I_{l o c}(l)=I_{0} \exp \left(-\sigma_{X} X l\right) \quad(\mathrm{S} 1-\mathrm{S} 4)
$$

where $l$ is the light path between the location considered and the pond top surface (m) and $I_{0}$ is the incident light intesnity at the pond top surface ( $\mathrm{W} \mathrm{m}^{-2}$, as PAR). The extinction coefficient for Chlorella vulgaris was shown to obey the following equation ${ }^{3}$ : $\sigma_{X}=A X^{B} \quad(\mathrm{~S} 1-\mathrm{S} 5)$

where $A$ and $B$ are empirical constants $\left(A=117.4 \mathrm{~m}^{2} \mathrm{~kg}^{-1} ; B=-0.200\right)$. As explained by Béchet et al. ${ }^{3}$, the dependence of the extinction coefficient was mostly due to the partial absorption of light by the sides of the small cultivation vessels. Indeed, for relatively high concentrations, the extinction coefficient was found almost constant and close to a value of $120 \mathrm{~m}^{2} / \mathrm{kg}$. As a result, the light distribution in the open pond was determined by the following equation:

$$
I_{l o c}(z)=I_{0} \exp (X z) \quad(\mathrm{S} 1-\mathrm{S} 6)
$$

where $z$ is the depth (m) and $\sigma$ equals $120 \mathrm{~m}^{2} \mathrm{~kg}^{-1}$.

\subsection{Temperature model}

The temperature model of Béchet et al. ${ }^{1}$ was used to determine the culture temperature in the open ponds. Table S1-S2 summarizes the values of the main model inputs. 
Table S1-S2: Model parameters values for the prediction of temperature in open ponds Symbol Description Value

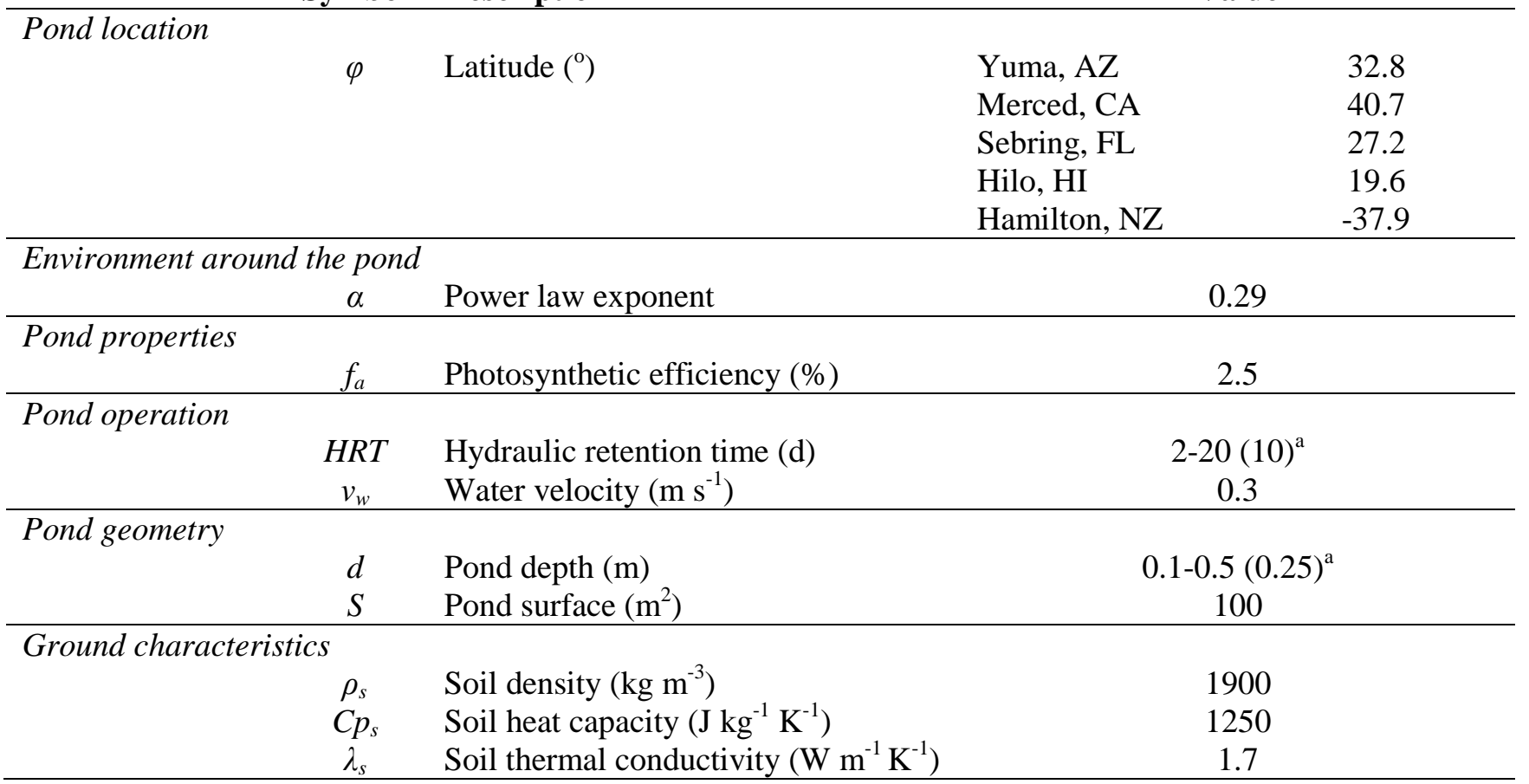

${ }^{a}$ Values in parenthesis correspond to 'standard' values; see Main manuscript. 


\section{S2: Impact of initial concentration on productivity predictions}

Figure S2-S1 shows that initial algal concentration value selected at the start of algal cultivation does not significantly impact the algal productivity predicted at any of the five climatic locations and for any hydraulic retention time (HRT) value.
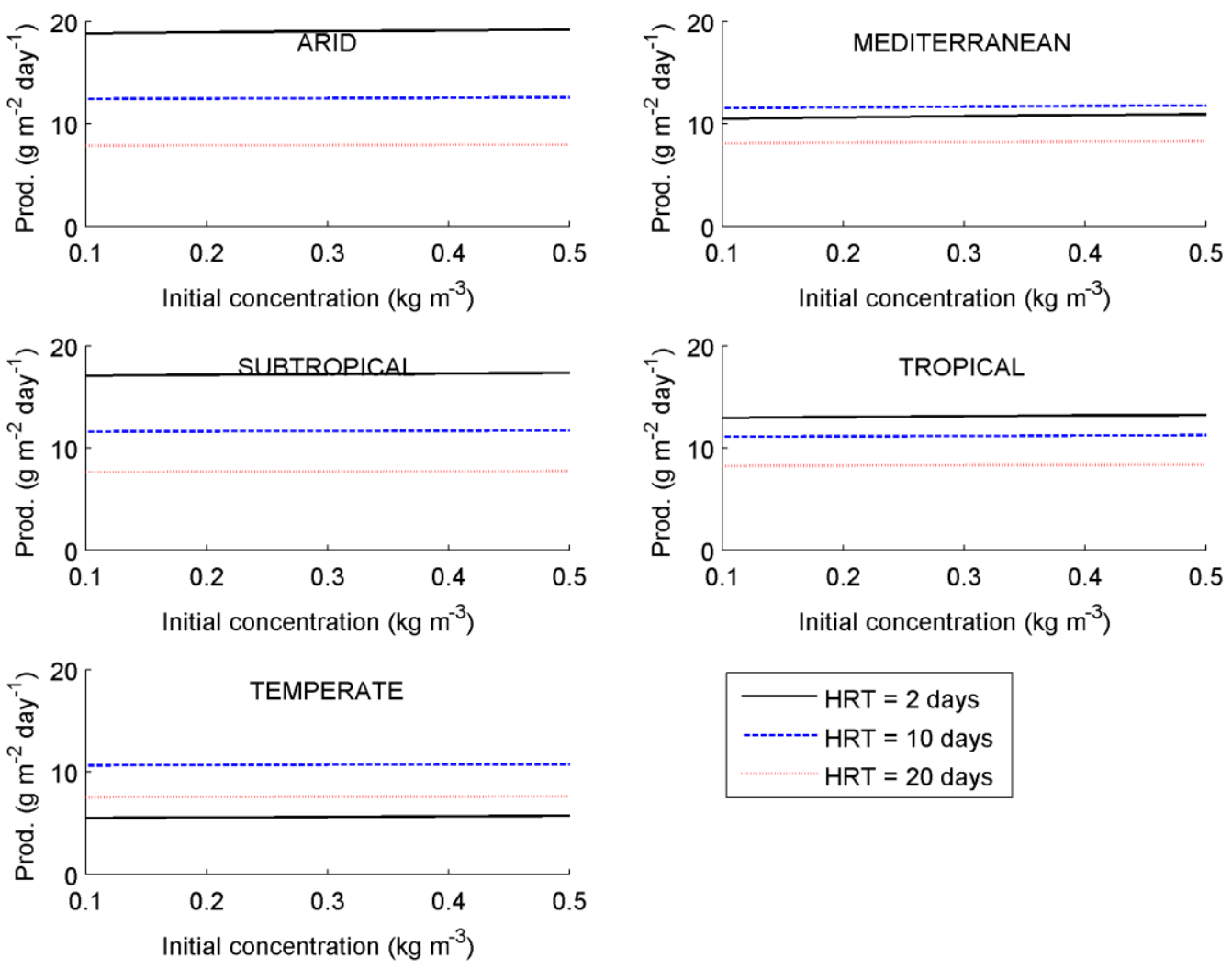

Initial concentration $\left(\mathrm{kg} \mathrm{m}^{-3}\right)$

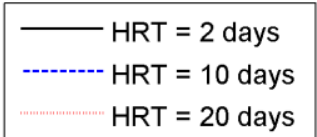

Figure S2-S1: Evolution of the yearly algal productivity with the initial algal concentration at five climatic locations for different HRT. 
S3: Impact of pond depth on productivity, water demand, and overheating risks at five climatic locations
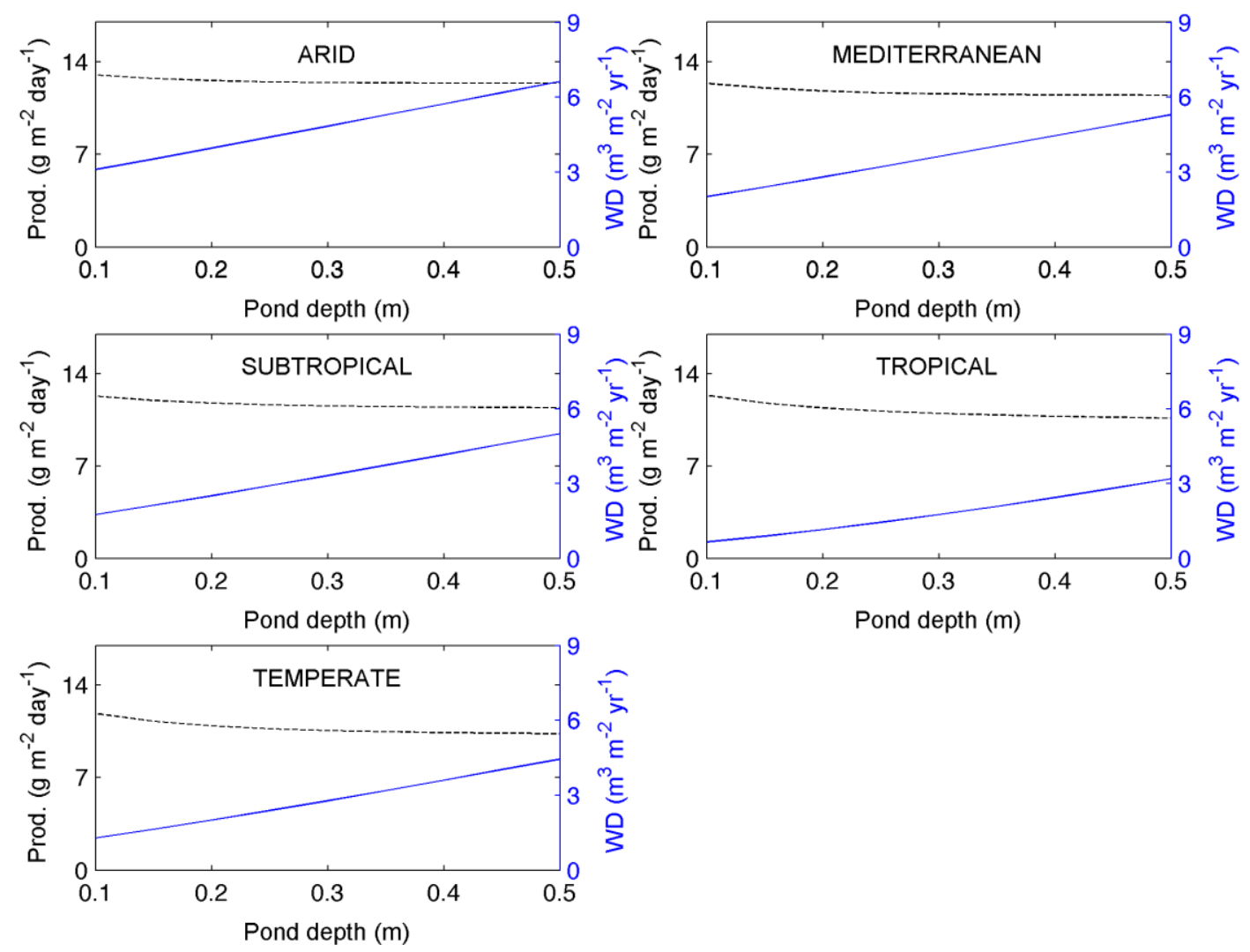

Figure S3-S1: Impact of pond depth (m) on net biomass productivity (black dashed-line) and water demand (blue plain line) during algal cultivation in open ponds when pond depth and HRT are held constant over the year (HRT $=10$ days). 

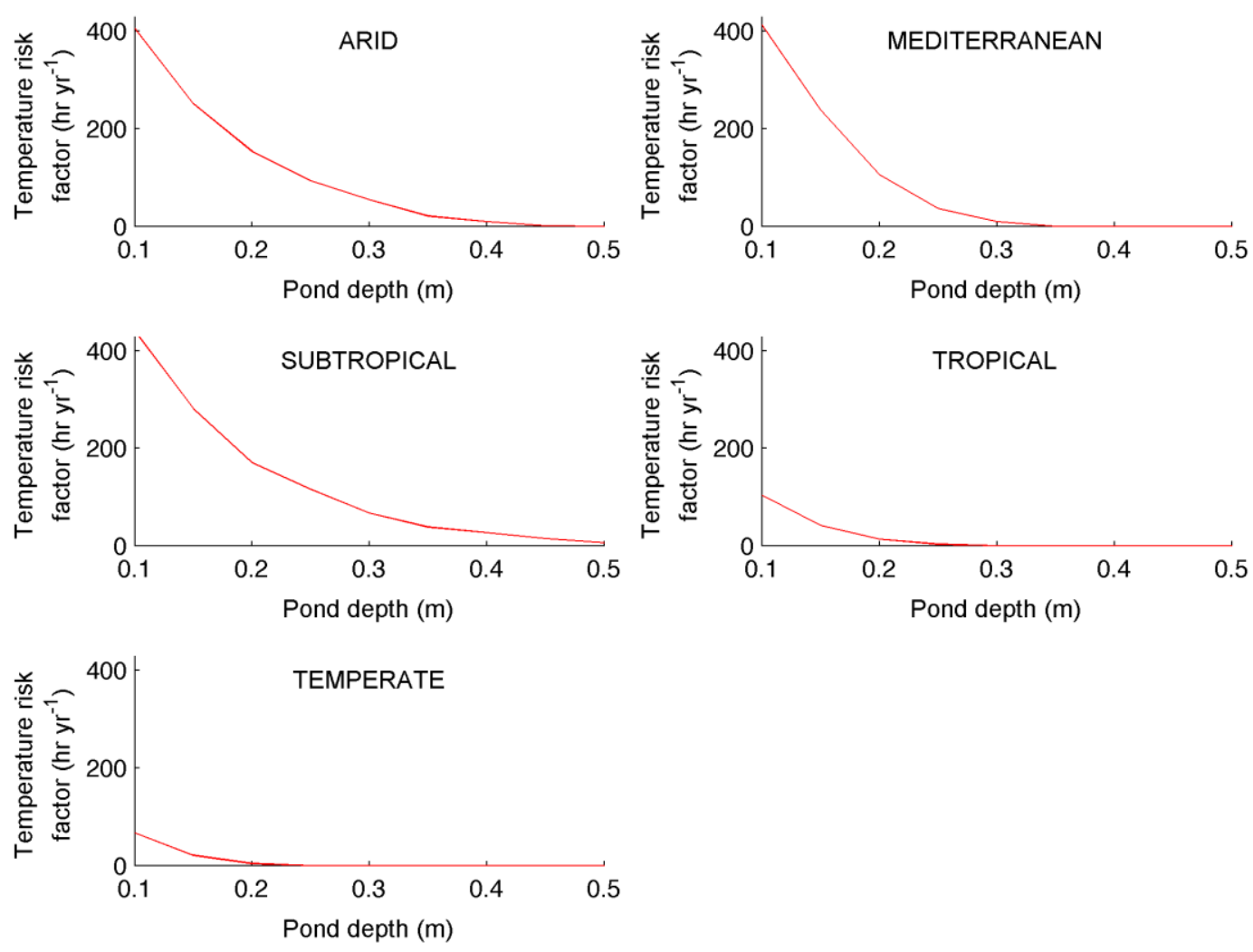

Figure S3-S2: Impact of pond depth (m) on the number of hours when pond temperature exceeds $35^{\circ} \mathrm{C}$ when pond depth and HRT are held constant over the year (HRT $=10$ days). 
S4: Impact of pond HRT on productivity and water demand at five climatic locations
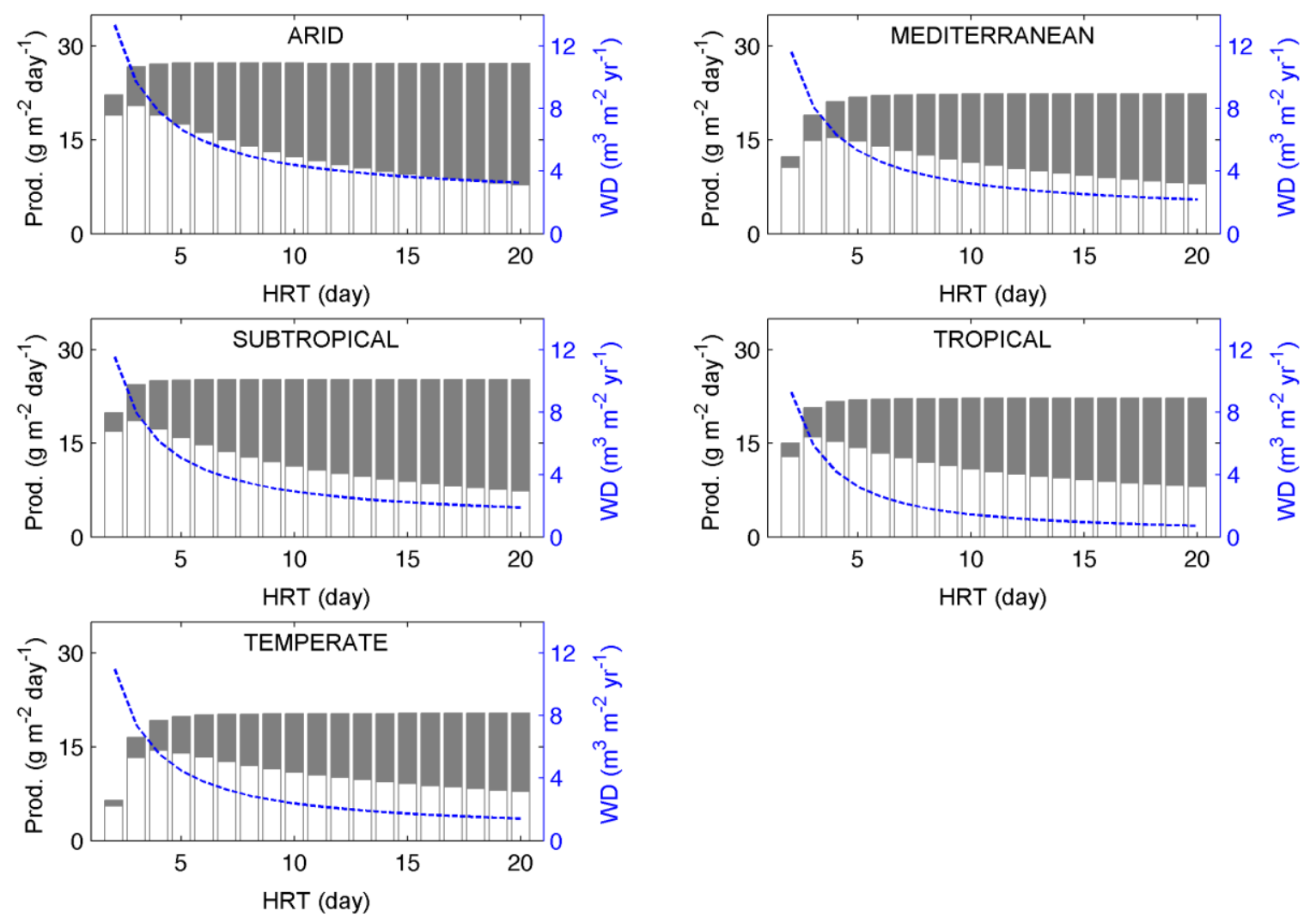

Figure S4-S1: Impact of HRT on net biomass productivity and water demand (WD) during algal cultivation in open ponds when pond depth and HRT are held constant over the year (pond depth $=0.25 \mathrm{~m}$ ). (White bar: net biomass productivity; Grey bar: respiration loss; Blue dashed-line: water demand) 
S5: Optimal HRT profiles at constant depth at five climatic locations
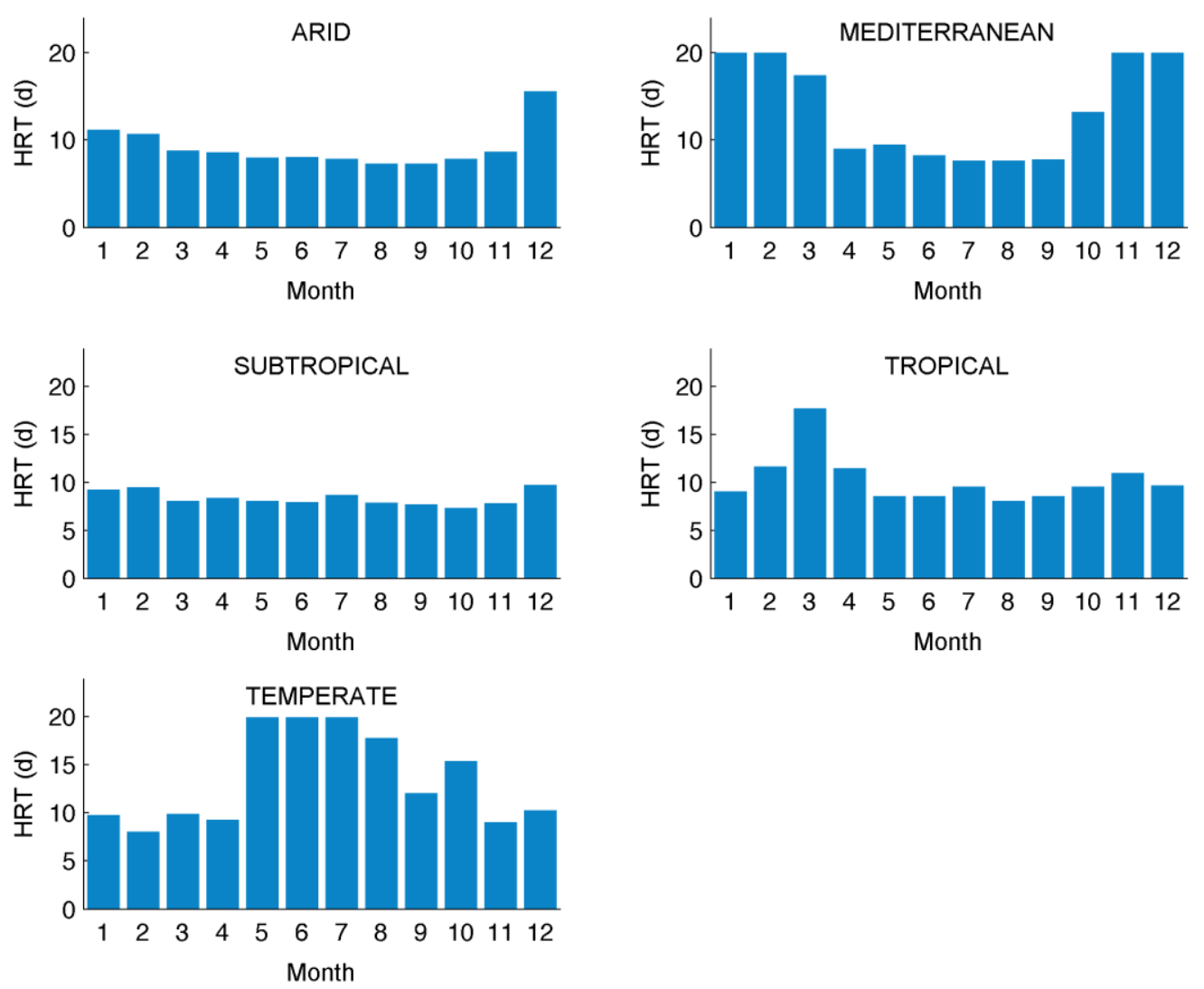

Figure S5-S1: Maximum HRT ensuring that respiration loss does not exceed 50\% of photosynthetic output each month (pond depth $=0.25 \mathrm{~m}$ ) 


\section{S6: Impact of the rainfall criterion on yearly productivity when depth and HRT are co-controlled under a water demand constraint}

Figure S6-S1 shows yearly productivity at five climatic locations when the water demand is limited at one time, two times and three times the amount of annual rainfall. Figure S6-S1 shows that $C$. vulgaris cultivation in arid, Mediterranean and tropical climate would not be feasible if the water demand must not exceed the yearly rainfall. This is explained by the fact that evaporation rates are relatively high and rainfall relatively lows at these locations. Interestingly, enabling a higher water use at the Mediterranean and tropical climates would significantly increase algal productivity (and land use efficiency) at these locations, as respiration rates would be significantly reduced. In a subtropical climate, freshwater availability does not restrain productivity because abundant rainfall allows operation at the optimal concentration minimizing respiration losses. The same conditions are reached in a temperate climate when water use is limited to three times the amount of rainfall. Finally, algal cultivation remains impossible at the arid climate under this water constraint as rainfall represents only a fraction of evaporation. 

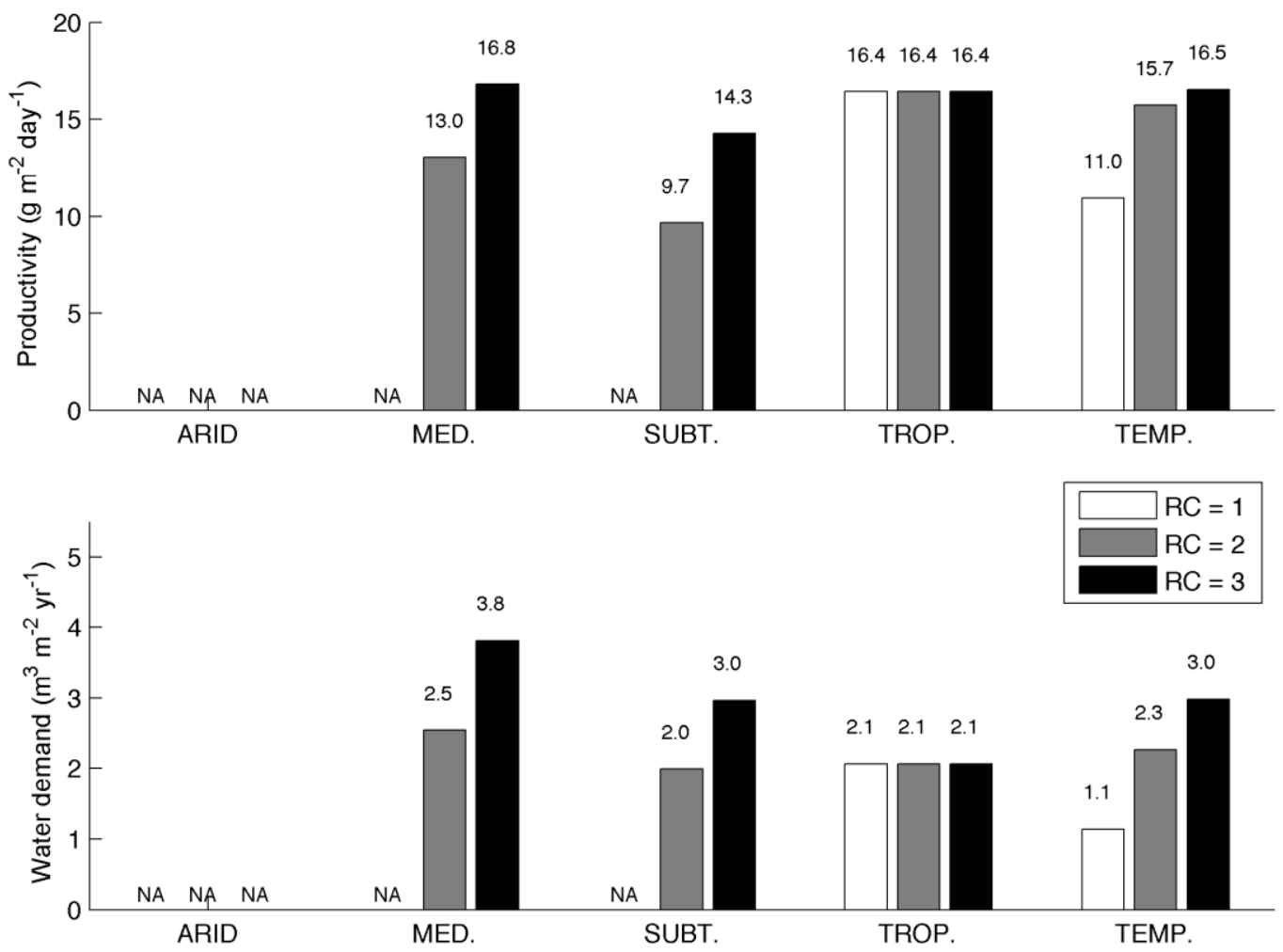

Figure S6-S1: Impact of the Rainfall Criterion (RC, defined here as the ratio of the yearly water demand over the annual rainfall) on annual productivity when pond depth and HRT are co-controlled. 


\section{References}

(1) Béchet, Q.; Shilton, A.; Park, J. B. K.; Craggs, R. J.; Guieysse, B. Universal temperature model for shallow algal ponds provides improved accuracy. Environ. Sci. Technol. 2011, 45 (8), 3702-3709.

(2) Béchet, Q.; Shilton, A.; Guieysse, B. Modeling the effects of light and temperature on algae growth: State of the art and critical assessment for productivity prediction during outdoor cultivation. Biotechnol. Adv. 2013, 31 (8), 1648-1663.

(3) Béchet, Q.; Chambonnière, P.; Shilton, A.; Guizard, G.; Guieysse, B. Algal productivity modeling: A step toward accurate assessments of full-scale algal cultivation. Biotechnol. Bioeng. 2015, 112 (5), 987-996.

(4) Béchet, Q.; Shilton, A.; Guieysse, B. Full-scale validation of a model of algal productivity. Environ. Sci. Technol. 2014, 48 (23), 13826-13833. 